\title{
Intracranial foreign body through the sagittal sinus: case report and review of literature
}

\author{
Roodrajeetsing Gopaul', Wen Shao Xiao ${ }^{1,2^{*}}$, Jun Yan $^{1}$ and Dang Zong Wei ${ }^{1}$
}

\begin{abstract}
Objective: To investigate therapeutic effect of surgery that removes an intracranial foreign body through the intracranial sagittal sinus with help of intraoperative navigation and intraoperative fluorescein angiography.

Methods: We performed operation on a patient with intracranial foreign body. Under guidance of intraoperative navigation, combined with intraoperative fluorescein angiography to avoid sagittal sinus damage, we opened the dura mater and removed the foreign body with minimally invasive technique.

Results: Surgical positioning was very accurate with neuronavigation, intraoperative fluorescein angiography displayed the venous drainage along the sagittal sinus in order to prevent its rupture; the intracranial foreign body was removed successfully without any post-operative complications.

Conclusion: Intraoperative navigation and intraoperative fluorescein angiography technologies to guide the removal of the foreign metal body inserted through the sagittal sinus have the following advantages: Accurate positioning, minimally invasive, reliable curative effect, quick postoperative recovery and overall fewer complications.
\end{abstract}

Keywords: Intracranial foreign body, The sagittal sinus, Surgical technologies

\section{Background}

Intracranial foreign bodies are generally due to penetrating head trauma through the nose, ear or orbits $[1,2]$. Penetrating trauma secondary to gunshot wounds are a common cause of injury in neurosurgical practice [3]. Penetrating craniocerebral injuries from objects such as needles, metal chopsticks,pieces of wood and nails, however, are rare $[1,4]$. Another common cause is insertion of foreign bodies through the anterior fontanelle in attempted infanticide [5]. Insertion of needles through the fontanel is a relatively easy attempt for child abuse. This has been reported from different countries such as Germany, United States, Turkey and Iran. There have been few case reports indicating infanticide using sewing needles (Table 1) in the literature. Meixner [6] was the first to publish such a case in the German literature in

\footnotetext{
* Correspondence: pawangopaul@yahoo.com

${ }^{1}$ Department of Neurosurgery, Guangxi Medical University, First Affiliated Hospital, 6 Shuang Yong Road, 530021 Nanning, Guangxi Zhuang Autonomous, People's Republic of China

${ }^{2}$ Guangxi Medical University, First Affiliated Hospital, 6 Shuang Yong Road,

530021 Nanning, Guangxi Zhuang Autonomous, People's Republic of China
}

1914, and the largest review till date has been performed by Abbas Amirjamshidi [7] adding their own six new cases and reviewing 40 previously reported cases.

Most of the cases reported in the literature were diagnosed incidentally. Intracranial needles can present later in life with symptoms of headache, seizures or altered behavior [8].

The most common symptoms are headache and epilepsy [7]. Most of them were identified in Turkey and Iran, with only a few cases in the Far East, North and Eastern Europe, and the United States [9]. Only One case was reported in China in 2001 [10]. There is very few patients with symptomatic intracranial needles previously reported. Amirjamshidi [7] reported six cases, four of which underwent surgical operation. One patient developed 'akinetic mutism' after cessation of anesthesia. Headache improved after the operation in two cases, and for the other one it remained unchanged. No cases with the needles passing through the sagittal sinus were reported. However, surgery that removed 
Table 1 Cases Reported in Literature since 1914

\begin{tabular}{|c|c|c|c|c|c|c|}
\hline $\begin{array}{l}\text { Author/ } \\
\text { reference }\end{array}$ & $\begin{array}{l}\text { Number } \\
\text { of cases }\end{array}$ & Year & Country & Age at presentation & Clinical onset & $\begin{array}{l}\text { Number of } \\
\text { needles }\end{array}$ \\
\hline Meixner [6]/1 & 2 & 1914 & Germany & 4 day; 43 years & NA & $1 ; 2$ \\
\hline Haun $[21] / 7$ & 1 & 1927 & Germany & 70 years & NA & 1 \\
\hline Gerlach and Jensen [22]/5 & 2 & 1958 & US; Germany & 16 months; 29 years & headache and epilepsy & $1 ; 2$ \\
\hline Askenasy [15]/3 & 2 & 1961 & Hungary; Poland & 23 years; 54 years & Convulsions; headache and vision disturbances & $1 ; 1$ \\
\hline $\begin{array}{l}\text { Ameli and } \\
\text { Alimohammadi [14]/2 }\end{array}$ & 2 & 1970 & Both in Iran & 31 years; 32 years & Headache and left hemiparesis; epilepsy & $1 ; 2$ \\
\hline Dimitrijevic [23]/4 & 1 & 1971 & Yugoslavia & 56 years & Acute head ache & 1 \\
\hline Jovicic et al. [24]/8 & 2 & 1974 & Germany & & NA & NA \\
\hline Ishi et al [25] 1/7 & 1 & 1977 & Japan & & NA & NA \\
\hline Abbassioun et al. [12]/30 & 3 & 1979 & Iran & $\begin{array}{l}24 \text { years; young man; } \\
4 \text { months }\end{array}$ & $\begin{array}{l}\text { Headache; incidental detection after trauma; } \\
\text { convulsion and vomiting }\end{array}$ & $2 ; 1 ; 1$ \\
\hline Barlas and Gökay [26]/22 & 2 & 1983 & Turkey & 29 years; 4 months & Headache; acute needle insertion & $1 ; 1$ \\
\hline Buzzi et al. [27]/34 & 1 & 1987 & Italy & 54 years & Unremarkable except for hypertension & 3 \\
\hline Rahimizadeh et al. [8]/32 & 6 & 1987 & $\begin{array}{l}5 \text { in Iran; } 1 \text { in } \\
\text { Afghanistan }\end{array}$ & $\begin{array}{l}9 \text { years; } 21 \text { years; } 22 \text { years; } \\
29 \text { years; } 55 \text { years; } 68 \text { years }\end{array}$ & $\begin{array}{l}\text { Headache or epilepsy in } 3 \text { cases; accidental } \\
\text { detection after trauma in } 2 ; \mathrm{TIA}^{a} \text { in } 1\end{array}$ & NA \\
\hline Notermans et al. [5]/33 & 1 & 1990 & Netherland & 12 years & $\begin{array}{l}\text { Headache, neck pain, vomiting, inability to } \\
\text { abduct left eye and asymmetric face on left side }\end{array}$ & 1 (Stylet) \\
\hline Prusty et al. [28]/19 & 1 & 1993 & India & NA & NA & NA \\
\hline Sener et al. [29]/24 & 1 & 1997 & Turkey & 20 years & Incidental detection & 3 \\
\hline Meng $[10] / 18$ & 1 & 2001 & China & 27 years & Incidental detection after trauma & $2+1$ \\
\hline Unal et al. [30]/16 & 1 & 2005 & Turkey & 10 years & Incidental detection & 1 \\
\hline Tun et al. [31]/26 & 1 & 2005 & Turkey & 45 years & Incidental detection After trauma & 1 \\
\hline Civelek et al. [32]/23 & 1 & 2006 & Turkey & 7 years & Acute onset after trauma & 1 \\
\hline Sucu and Gelal [33]/25 & 1 & 2006 & Turkey & 29 years & Incidental detection after trauma & 1 \\
\hline Teegala et al. [11]/20 & 1 & 2006 & India & 4 years & Incidental detection & 2 \\
\hline Tuncer et al. [16]/27 & 1 & 2007 & Turkey & 32 years & Seizure attack & 1 \\
\hline Yilmaz et al. [34]/28 & 1 & 2007 & Turkey & 10 years & Fever, headache, and vomiting & 5 \\
\hline Yolas et al. [35]/29 & 1 & 2007 & Turkey & 9 years & Seizure attack & 1 \\
\hline Ashrafi et al. [36]/31 & 1 & 2007 & Iran & 42 years & Acute headache & 2 \\
\hline Balak et al. [13]/21 & 1 & 2008 & Turkey & 10 years & Seizure attack & 1 \\
\hline Present case & 1 & 2012 & China & 25 years & Absence Epilepsy & 1 \\
\hline
\end{tabular}

${ }^{\mathrm{a}} T I A$ transient ischemic attack, NA not applicable (Data missing)

needle from the sagittal sinus successfully has not been reported till date.

We here report a 25-year old woman with absence seizure resulting from the presence of sewing needle situated in the brain. The ethical clearance from our hospital was cleared.

\section{Case presentation}

A 25-year-old woman was admitted to the emergency department of a local hospital with absence seizure. Since the beginning of 2012, patient suffered from unexplained absence seizure repeatedly many times. Each time the attack lasts for a few minutes. Patient returns back to normal after waking, with no convulsions. A diagnosis of absence seizure was made. Patient took traditional Chinese medications, but the symptoms persisted. In order to further diagnose and treat the patient, she was transferred to the neurology department of our hospital.

On admission she was alert and her neurological examination was normal, there were no focal neurological examination findings. There was no previous history of absence seizure and her past medical history was unremarkable. She reported no history of head trauma or injury. Laboratory finding of the cerebrospinal fluid were normal. Blood routine, urine routine test were normal. Skull radiography revealed the presence of a metal foreign body situated in a craniocaudal direction along the midline (Fig. 1a and b). Also, Computerized tomography $(\mathrm{CT})$ of the brain was performed and showed a metal foreign body embedded in the right frontal lobe, 

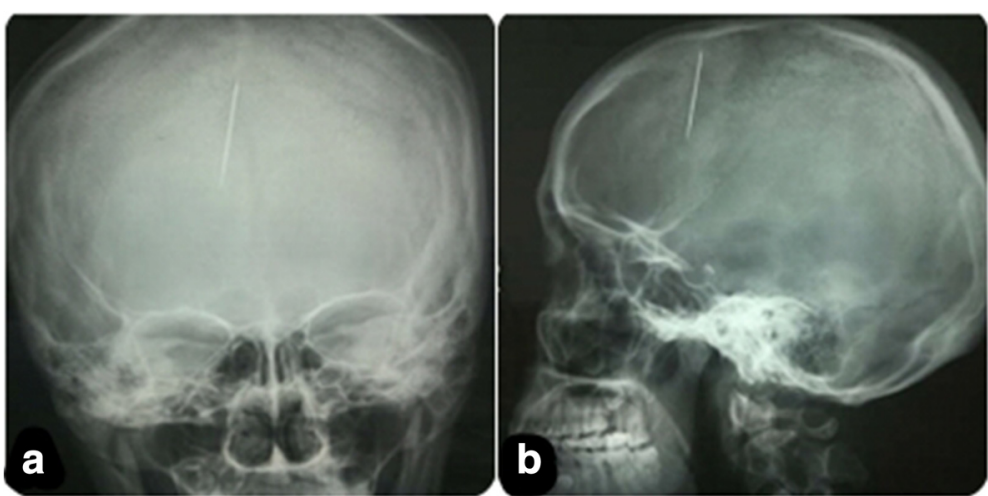

Fig. 1 X-Ray of Skull a. AP view. b. Lateral View

passing through the sagittal sinus (Fig. 2). Intracranial bleeding, arteriovenous malformation and any intracranial occupying lesion were not detected by the CT scan. CTV/CTA reconstruction showed close proximity of metal foreign body and the major blood vessels (Fig. 3).

The patient has no vivid memory of how the needle was introduced at that position and her family also claimed to be unaware of such an incident. Based on the foreign body's location, we deduce that it might have been inserted through the anterior fontanel during early childhood.

An electroencephalography (EEG) recording was performed 2 days after an absence seizure but no abnormal findings were recorded. The patient was given antiepileptic medication orally for 3 months but there were repeated

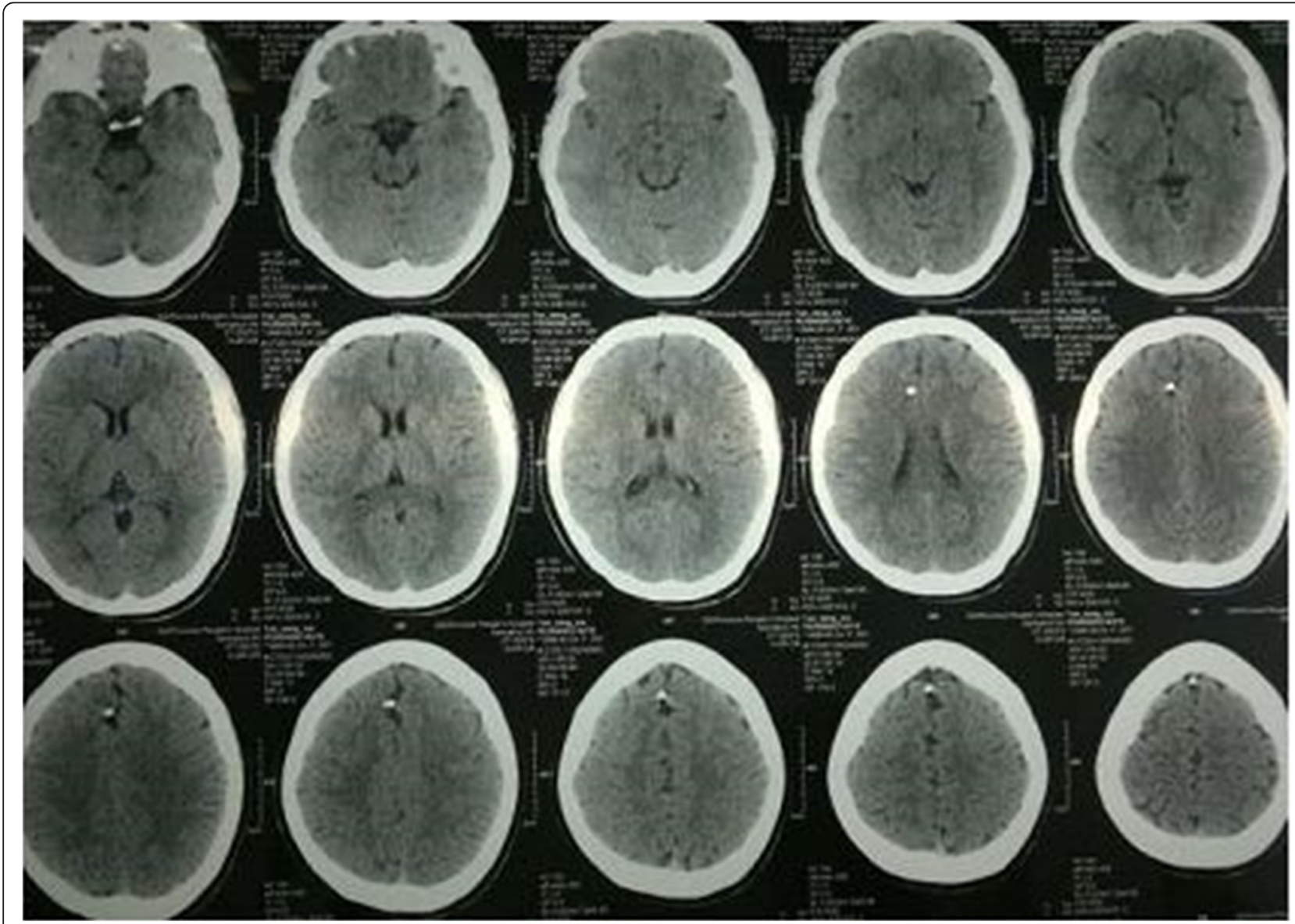

Fig. 2 Computed Tomography of Skull showing needle 




Fig. 3 Computed Tomography 3D angiography reconstruction showing relation of needle to Sagittal Sinus. a. Craniocaudal View. b. Caudocranial View

episodes. We deduced that the intracranial foreign body could be the reason of the absence seizures. Surgical intervention was considered as a treatment option, patient and family members were approached and they gave consent to remove the foreign body.

Intracranial foreign bodies are a rare entity. The most common presentations are headaches and seizures. The management of such patients is sometimes challenging. We successfully carried out the surgery for the patients and removed a sewing needle completely. There was no harm to the sagittal sinus and subcallosal vessels. Postoperative, neither headache nor epilepsy affected the patients.

Surgical intervention was attempted to remove the metal foreign body. A small craniotomy was made after localizing the needle with marked skull $\mathrm{x}$-rays taken in $\mathrm{AP}$ and lateral views. The patient underwent general anesthesia in a supine position.

Operation steps are as follows:

1. According to the CT scan preoperatively and intraoperative navigation guidance, a $5 \mathrm{~cm}$ incision through the midline was made. Drilling was done on the sagittal sinus. $3 \mathrm{~cm}$ bone flap was made.

2. To understand the relationship between the metal foreign body and the blood vessels around it, we performed intraoperative fluorescein angiography using indocyanine green dye. Indocyanine green dye was intravenously administered and with help of infrared light frequencies from the microscope, circulation of blood was observed to prevent damage of draining veins. Dura was cut open near the superior sagittal sinus. Adhesions were dissected and metal foreign body was fully exposed (Fig. 4). Figure 4a shows the surgical field before dissection of the dura mater. Figure $4 \mathrm{~b}$ shows the intraoperative fluorescein angiography using intravenous indocyanine green dye. Bright structures on the angiography show blood vessel distribution. Figure $4 \mathrm{c}$ illustrates the naked eye appearance of the rusted foreign metal body. Figure $4 \mathrm{~d}$ shows the surgical field after removal of the foreign metal body.

3. We found that the intracranial metal foreign body was rusted. The upper tip of the foreign body passed through the sagittal sinus and the lower tip of the foreign body was adhered closely with the blood vessels around the callosum and its branches. Adhesion between the needle, blood vessels and brain tissues were dissected and the upper end of the intracranial foreign body detached leaving a free end. After removing the intracranial foreign body, it seemed like a sewing needle. The free end of the needle attached to the falx was thoroughly examined for inspection of residuals. The surgical vision was properly rinsed and disinfected.

4. The metal foreign body was completely removed under the microscope (Fig. 5). Hemostatic gauze and gel-foam was applied on the wound. Dura was sutured tightly to prevent postoperative cerebrospinal fluid leakage. Titanium plates and screws were used to fix the cranial bone.

Surgical positioning was very accurate with help of the intraoperative navigation. Intraoperative fluorescein angiography displayed venous drainage across the sagittal sinus in order to avoid its damage. CT scan on the following morning of surgery was taken and 1 year post surgery CT is shown in Fig. 6. The foreign body was removed successfully without any complications. The patient has been followed for more than 3 years and has remained asymptomatic with impeccable recovery.

\section{Discussion}

History

Intracranial foreign bodies such as metallic objects, wood and bone are usually due to penetrating injuries through 




Fig. 4 Intraoperative view of surgical region with intraoperative fluorescein angiography. a. Dura Mater in situ, gross appearance of surgical field. b. Intraoperative fluorescein angiography view. c. Dura mater excised and foreign body is clearly seen- rested and passing through the superior sagittal sinus. d. Foreign body removed, hemostasis achieved

the cranial bones, orbit, and ear $[1,2]$. Sewing needles are among the more unusual foreign bodies that may be found in the brain. Such incidents often happen in infancy or early childhood (before the closure of fontanelles) and may not present until much later in life with symptoms like headache, seizures or altered behavior [11]. The reported cases in the literature are from different countries including Germany, the United States, Turkey, Poland, Hungary, Yugoslavia, and Iran (Table 1).

Our patient's skull X-ray reveals that intracranial metal foreign body could be a sewing needle. This female patient was raised by her grandmother when she was young. She did not recall any history of trauma. There are no signs of bending extrusions on the metal foreign body. It is quite

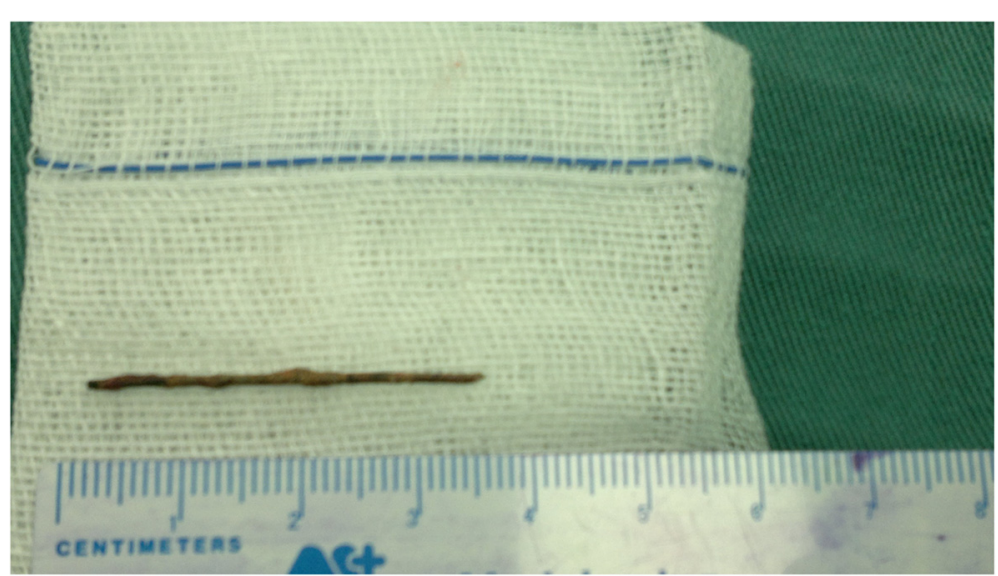

Fig. 5 Removed needle after surgery 




Fig. 6 Postoperative Computed Tomography follow up. a. CT scan of brain 1 year post-op. b. CT scan of brain 3 years post-op

impossible that sewing needle penetrated into the brain through the cranium as a result of trauma or any accident.

Cranial X-ray shows that the metal foreign body is in front of the coronal suture and near the sagittal sinus. This is the position of the bregma in infants. Therefore the intracranial metal foreign body of this patient should have been inserted into the brain before the closure of anterior fontanelle.

The cause of this intracranial metal needle is not clear. There have been reports of voluntary infanticide earlier in literature. The offending person is usually the stepmother, but psychopathic mother, aunt, stepsister, and baby sitter have also been mentioned as offenders [12,13]. If the first homicide attempt were not successful, a second, third, or even more attempts might be performed to harm the victim [14]. There are reports of insertion of needles to the other parts of victims' body such as chest and abdomen [12-16]. But the patient presented here is from the Zhuang ethnicity. Girls usually wear colorful traditional dress with many metal pins attached to hold the decorations in place. This could be the underlying reason in our case as the patient's history did not reveal any incidence of child abuse.

\section{The clinical symptoms}

There are many reports of foreign objects retained in the brain for long periods of time without any symptoms $[8,16]$. Tuncer et al. [16] reported a man who first experienced a Generalized Tonic-Clonic (GTC) seizure at the age 32 years old. Ameli et al. [14] reported a 32-year-old man who had developed epilepsy 8 years earlier. Sewing needles were visible in both cases on skull radiography. Late-onset epilepsy due to an intracranial needle have been reported previously $[8,15]$.

Headache and epilepsy are the main symptoms and they often appear when the patient reaches adulthood [12]. Other rare clinical features of intracranial needles are hemiparesis and gait disturbance, brain abscess, hemi-chorea and cranial nerve palsy $[9,17,18]$. However, to date, no case presenting with absence seizure has been described.

The intracranial metal foreign body has toxic effect on brain tissue. This leads to the secondary infection and the intractable epilepsy. It also leads to focal neurologic symptoms. The movement of the foreign body also can cause secondary damage.

In our case, apart from being susceptible to colds and fevers during childhood, the patient has unremarkable medical history. Mental development of the patient was normal. Appearance of clinical symptom of absence seizure only until the age of 25 years old makes this case is rare. 


\section{Management}

In our case, the intracranial metal foreign body passed through the sagittal sinus. Tuncer et al. [16] suggests that surgical removal is not indicated in asymptomatic patients. Similarly, Ilbay et al. [19] recommends conservative approach if the patient is symptom-free and diagnosis is purely incidental and there is no risk of infection. Also, Abbassioun et al. [12] point out that metallic foreign bodies are much better tolerated in the brain than fragments of bone.

According to the majority of authors, the therapy of choice should consist of follow-up alone when no clinical signs or symptoms are present. Antiepileptic drugs should be reserved only for patients with seizures [9]. Amirjamshidi et al. [7] described that there was no absolute indication for removing intracranial sewing needles detected in the later decades of life. Vedat Ali [20] points out that patient with intracranial needles may present late in life with epilepsy or status epilepticus. They suggest that surgical intervention is unnecessary if seizures are under control with antiepileptic drug therapy.

However, in this case, the patient was young and new onset of absent epilepsy was observed. With the use of intraoperative navigation and positioning, intraoperative fluorescein angiography to avoid sagittal sinus rupture and use of microscope to attain minimally invasive approach, the treatment of intracranial metal foreign body tends to be more attainable with minimum damage to the brain tissues and thus postoperative complications.

\section{Conclusion}

With the improvements of surgical technologies and equipment in recent years, the treatment of intracranial metal foreign body tends to be more in reach of a neurosurgeon.

In our case, we removed needle metal through the sagittal sinus by use intraoperative navigation providing accurate position and use of intraoperative fluorescein angiography to avoid damage of draining veins while cutting open the dura mater near the superior sagittal.

Advanced surgical technologies have the following advantages: accurate positioning, minimally invasive, reliable curative effect, quick postoperative recovery and overall fewer complications.



\section{Authors' contributions}

GR participated in the sequence alignment and drafted the manuscript. WZD participated in the sequence alignment. GR participated in the design of the study and performed the statistical analysis. All authors conceived of the study, and participated in its design and coordination

and helped to draft the manuscript. All authors read and approved the final manuscript.

\section{Competing interests}

The authors declare that they have no competing interests.

\section{Consent}

Written, informed consent was obtained from the patient for publication of this case report and accompanying images.

Received: 28 April 2015 Accepted: 1 February 2016

Published online: 18 June 2016

\section{References}

1. Lee DH, Seo BR, Lim SC. Endoscopic treatment of transnasal intracranial penetrating foreign body. J Craniofac Surg. 2011;22(5):1800-1.

2. Kuroiwa T, Tanabe H, Ogawa D, et al. Chopstick penetration of the posterior cranial fossa: case report. Surg Neurol. 1995;43:68-9.

3. Moores LE. Management of migrating intracranial bullets: lessons learned from surviving an AK-47 bullet through the lateral brainstem. World Neurosurg. 2012;77(3-4):481-3.

4. Ashkenazi E, Mualem N, Umansky F. Successful removal of an intracranial needle by an ophthalmologic magnet: case report. J Trauma. 1990;30:114-5.

5. Notermans NC, Gooskens RH, Tulleken CA, et al. Cranial nerve palsy as a delayed complication of attempted infanticide by insertion of a stylet through the fontanelle. J Neurosurg. 1990;72:818-20.

6. Meixner K. To: ungursuchi an Kindern durch Einstechen von Nadeln in den Kopf. Dtsch Z Gesamte Gerichtl Med. 1914:47:382-6.

7. Amirjamshidi A, Ghasvini AR, Alimohammadi M, Abbassioun K. Attempting homicide by inserting sewing needle into the brain report of 6 cases and review of literature. Surg Neurol. 2009;72(6):635-44.

8. Rahimizadeh A, Sabouri-Daylami M, Tabatabi M, Rabani M, Hadadian K. Intracranial sewing needles. Neurosurgery. 1987;20:666 (letter).

9. Sturiale CL, Massimi L, Mangiola A, Pompucci A, Roselli R, Anile C. Sewing needles in the brain: infanticide attempts or accidental insertion? Neurosurgery. 2010;67(4):E1170-9.

10. Meng X. Traffic injury or attempted infanticide? Forensic Sci Int. 2001;122(1):73-4

11. Teegala R, Menon SK, Panikar D. Incidentally detected intracranial sewing needles: an enigma. Neurol India. 2006;54:447.

12. Abbassioun $\mathrm{K}$, Ameli NO, Morshed AA. Intracranial sewing needles, review of 13 cases. J Neurol Neurosurg Psychiatry. 1979;42:1046-9.

13. Balak N, Güçlü G, Karaca I, Aksoy S. Intracranially retained sewing needle in a child: does the rust on the needle have any implication? Eur J Trauma Emerg Surg. 2008:34:159-62.

14. Ameli NO, Alimohammadi A. Attempted infanticide by insertion of sewing needles through fontanelles. Report of 2 cases. J Neurosurg. 1970;33:721-3.

15. Askenasy HM, Kosary IZ, Braham J. Sewing needles in the brain with delayed neurological manifestations. J Neurosurg. 1961;18:554-6.

16. Tuncer $N$, Yayci N, Ekinci G, Inanici MA, Elmaci I. Intracranial sewing needle in a man with seizure: a case of child abuse? Forensic Sci Int. 2007;168(2-3): 212-4. 24.

17. Nishio $Y$, Hayashi N, Hamada H, Hirashima Y, Endo S. A case of delayed brain abscess due to a retained intracranial wooden foreign body: a case report and review of the last 20 years. Acta Neurochir. 2000;146(8):847-50.

18. Alp R, Ilhan Alp S, Ure H. Two intracranial sewing needles in a young woman with hemi-chorea. Parkinsonism and Related Disorders. 2009;15(10):7956.

19. Ilbay K, Albayrak BS, Ismailoglu O, Gumustas S. Letter to the editor-an incidental diagnosis of four adjacent intracranial sewing needles in a 16- year-old boy: a survivor of an infanticide attempt? J Forensic Sci. 2011;56(3):825.

20. Yurekli VA. Status epilepticus in a 52-year-old woman due to intracranial needle. Seizure. 2012:21(8):652-4.

21. Haun K. Beitrag zur Lehre vom Kindesmord. Berlin Heidelberg: Springer; 1927.

22. Gerlach J, Jensen HP. Intracranial sewing needles, an unusual cause of headaches. Zentralbl Neurochir. 1958;18(2-3):127-35.

23. Dimitrijevic D. Mordversuch mit her Nahnadel. Illustrierte. 1971;22:7.

24. Jovicic V, Keler A, Milenkovic Z. Two cases of intracerebrally located foreign bodies (sewing needle). Fortschr Geb Rontgenstr Nuklearmed. 1974;121(6):785.

25. Ishi N, Umezaki H, Mukai K. A case of brainstem trauma due to insertion of a sewing needle. No Shinkei Geka. 1977;5(13):1395. 
26. Barlas O, Gökay H. Sewing needle injuries of the brain. Neurosurgery. 1983; 13(1):105.

27. Buzzi S, Buzzi G, Buzzi A, Baccini C. Hypothalamic syndrome in a woman with three sewing needles in the brain. Lancet. 1987;1:1313.

28. Prusty $G$ et al. Sewing needle in the brain [Letter]. Neurol India. 1993;41 (1):51.

29. Sener RN. Intracranial sewing needles in a 20-year-old patient. J Neuroradiol. 1997;24(3):212-4.

30. Unal $\mathrm{N}$ et al. Asymptomatic intracranial sewing needle: An unsuccessful infanticide attempt? Pediatr Int. 2005;47(2):206-8.

31. Tun K et al. Intracranial sewing needle. J Clin Neurosci. 2006;13(8):855-6.

32. Civelek $E$ et al. [Penetrating transorbital intracranial foreign body]. Ulus Travma Acil Cerrahi Derg. 2006;12(3):245-8.

33. Sucu HK, Gelal F. Intracranial metallic foreign body presenting with a unique route of introduction into the brain. Neurol India. 2006;54(2):224.

34. Yilmaz N, Kiymaz N, Yilmaz C. Intracranial foreign bodies causing delayed brain abscesses: intracranial sewing needles. Case illustration. J Neurosurg. 2007;106:323.

35. Yolas $C$ et al. Intracerebral sewing needle. Pediatr Neurosurg. 2007;43(5):421-3.

36. Ashrafi H, Boostani R, Nazarbaghi, et al. Two Sewing Needles in the Brain: A Case Report. Iran J Med Sci. 2007;32(4):254-5.

Submit your next manuscript to BioMed Central and we will help you at every step:

- We accept pre-submission inquiries

- Our selector tool helps you to find the most relevant journal

- We provide round the clock customer support

- Convenient online submission

- Thorough peer review

- Inclusion in PubMed and all major indexing services

- Maximum visibility for your research

Submit your manuscript at www.biomedcentral.com/submit
Biomed Central 